\title{
Effects of Powder Characteristics on Rheological Properties of Alumina Slurries
}

\author{
Wen-Jie YUAN", Qing HUANG, Cheng-Ji DENG and Hong-Xi ZHU \\ The State Key Laboratory of Refractories and Metallurgy, Wuhan University of Science and \\ Technology, Wuhan 430081, China \\ *yuanwenjie@wust.edu.cn
}

Keywords: Powder characteristic, Alumina slurry, Particle size distribution.

\begin{abstract}
Effects of powder characteristics on rheological properties of alumina slurries were preliminarily investigated by measuring the particle size distribution and flow curves under steady and oscillatory shear conditions. The particle size distribution of three kinds of alumina fine powders was fitted based on Rosin-Rammler distribution. The fractal dimension of the particle size distribution for alumina powders was related to powder characteristics. The increasing of the average particle size of alumina from 2.73 to $4.96 \mu \mathrm{m}$ led to higher yield stress of slurries ranging from 0.015 up to $0.063 \mathrm{~Pa}$. The rheological properties of alumina slurries varied not only with the particle size and its distribution but also with other factors such as morphology and surface status.
\end{abstract}

\section{Introduction}

Rheological properties of slurries or suspensions with solid particles are extremely important for ceramic processing, which depend on the characteristics of materials [1]. For different shaping processes including gel casting, tape casting and slip casting, the requirements for slurries are varied [2]. The flow properties of slurries affect the subsequent drying and sintering processes. The mixing of refractory castables is influenced by particle size distribution and the water addition. The maximum flow values of castables were expected to be achieved by a minimum of mixing energy [3].

Alumina fine powders were widely used in advanced ceramics and refractories. The rheological behavior of alumina suspensions with the solid content, dispersant and modification process has been discussed [4-6]. However, castables are composed of coarse aggregates and matrix. Alumina as a part of matrix could have great impact on the flowability and strength of castables. The interactions among alumina fine powders and other components such as microsilica and tabular alumina were complex. Moreover, various alumina powders prepared by different producers presented respective properties. Therefore effects of powder characteristics on rheological properties of alumina slurries were separately investigated in the present work.

\section{Experimental Procedure}

Three kinds of alumina fine powders made by different companies were selected for all experiments. The particle size distribution of alumina fine powders was measured by Mastersizer (MS2000G, Malvern, UK). Alumina slurries with the solid content of 40 vol\% were prepared by stirring alumina powders with distilled water for $5 \mathrm{~min}$. In order to compare effects of powder characteristics on rheology, no dispersion agent was used. The rheology of all prepared slurries was evaluated using a rheometer (MCR301, Anton Paar, Austria). Shear stress-shear rate tests were carried out on various alumina slurries by increasing shear rate from 0.1 to $100 \mathrm{~s}^{-1}$. Strain sweep tests with strain from 0.01 to $100 \%$ were carried out at a constant frequency $(1.59 \mathrm{~Hz})$ under oscillatory shear conditions. Frequency sweep experiments were performed ranging from 0.1 to $100 \mathrm{~Hz}$ at strain amplitude of $0.05 \%$. 


\section{Results and Discussion}

The cumulative and frequency distribution of three kinds of alumina powder are shown in Fig. 1(a) and 1(b) respectively. From the shape of curves for frequency distribution, there was an enrichment of smaller particles for all alumina powders. It can be seen that powders A and C were bimodal, and powder B was monomodal.

According to Rosin-Rammler distribution, cumulative fraction $Y$ of powders less than size $x$ was expressed as [7]

$$
Y=1-\exp \left(-x / x_{0}\right)^{b}
$$

where $b=$ constant describing the powder uniformity, and $x_{0}=$ characteristic particle size. The fractal dimension of particle size distribution was defined as $D=3-b$ based on fractal theory raised by Mandelbrot [8]. The results of fitting data with typical particle size are listed in Table 1 . It could be demonstrated that particle size distribution of alumina powders exhibited fractal characteristics because $R^{2}$ values were more than 0.99 . The average particle size of powder $C$ was least, but it contained more ultrafine powders less than $1 \mu \mathrm{m}$. While the average particle size of powder B was larger, and its uniformity was higher $(b=1.699)$. The fractal dimension of alumina powders ranging from 1.3-1.8 was equivalent or less than fine grinding quartz [8].
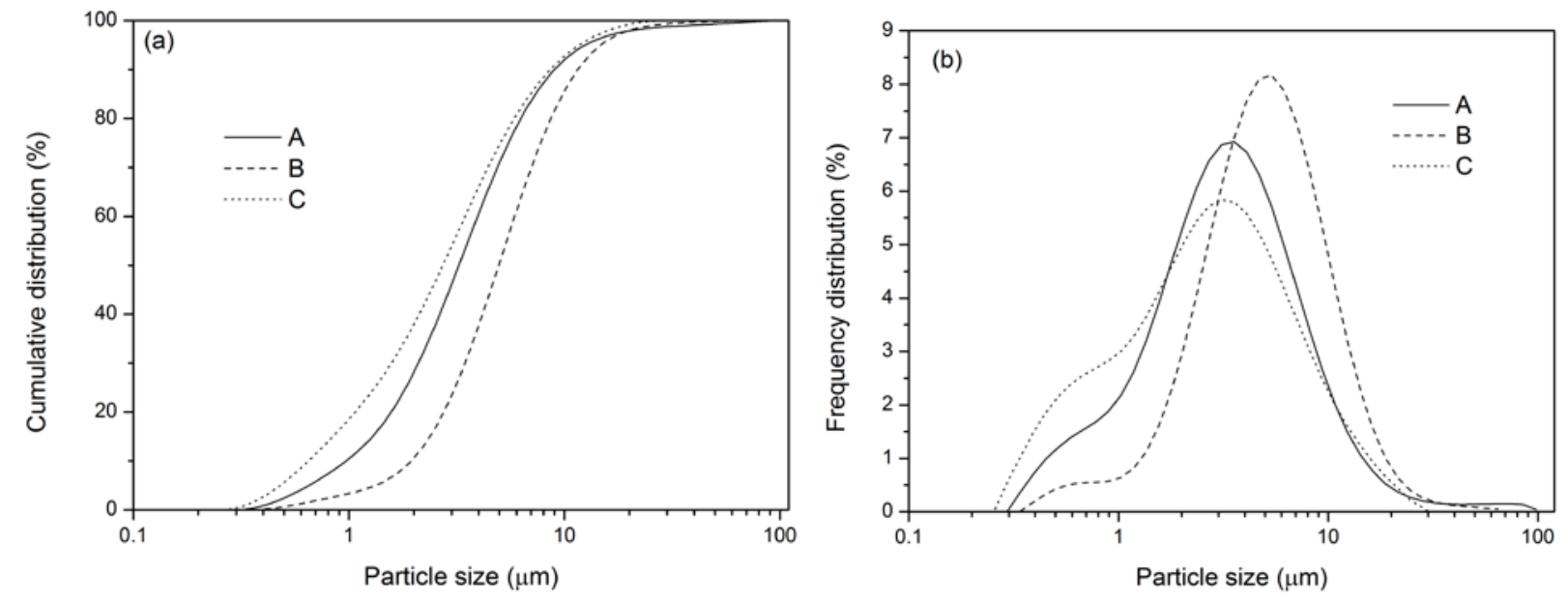

Fig. 1 Particle size distribution of three kinds of alumina powders: (a) cumulative distribution and (b) frequency distribution

Table 1 Typical particle size and fractal dimension D of alumina

\begin{tabular}{ccccccc}
\hline Alumina & $\mathrm{D}_{10}(\mu \mathrm{m})$ & $\mathrm{D}_{50}(\mu \mathrm{m})$ & $\mathrm{D}_{90}(\mu \mathrm{m})$ & $x_{0}(\mu \mathrm{m})$ & $b$ & $D$ \\
\hline $\mathrm{A}$ & 0.97 & 3.24 & 8.96 & 4.41 & 1.405 & 1.595 \\
$\mathrm{~B}$ & 1.95 & 4.96 & 11.51 & 6.43 & 1.699 & 1.301 \\
$\mathrm{C}$ & 0.65 & 2.73 & 8.59 & 3.85 & 1.195 & 1.805 \\
\hline
\end{tabular}

The aim of the present work was to discuss the influence of powder characteristics on rheological behavior of alumina slurries. Slurries with a constant solid content of 40 vol\% were analyzed. Figure 2 shows that the changes of shear tress and viscosity values with shear rate depended on the types of alumina. It could be seen that the shear stress increased with the shear rate as a whole (Fig. 2(a)). Less shear stress of slurry containing powder $C$ corresponded to smaller particle size. Except for the fluctuation of viscosity values at low shear rate, the changes of viscosity with shear rate for slurries containing powders $\mathrm{A}$ and $\mathrm{C}$ indicated the shear-thickening behavior, which was attributed to the formation of hydrodynamic clusters or flocculation structure [9]. The slop of curve C was much less 
than that of curve A. There was a transition shear-thinning to shear-thickening for slurry containing powder $\mathrm{B}$ at shear rate of $5 \mathrm{~s}^{-1}$, which was similar with the results in Ref. [2].

It is well known that several different models can be used to fit the flow curve of slurry [10]. The flow curves in Fig. 2 were fitted based on Herschel-Bulkley model, which defined shear stress $\tau$ as

$$
\tau=\tau_{y}+K \dot{\gamma}^{n}
$$

where $\tau_{y}$ =yield stress, $K=$ consistency index, $\dot{\gamma}$ =shear rate and $n=$ flow behavior index [11]. The maximum viscosity method is more representative and reproducible. So the yield stress of alumina slurries determined from curves of viscosity vs shear stress (not shown in fulltext) as well as the coefficients of Herschel-Bulkley model was listed in Table 2. Flow behavior index $n$ of more than 1 represented the shear-thickening behavior. Consistency index $K$ and yield stress $\tau_{y}$ of slurries were proportional to the particle size of alumina.
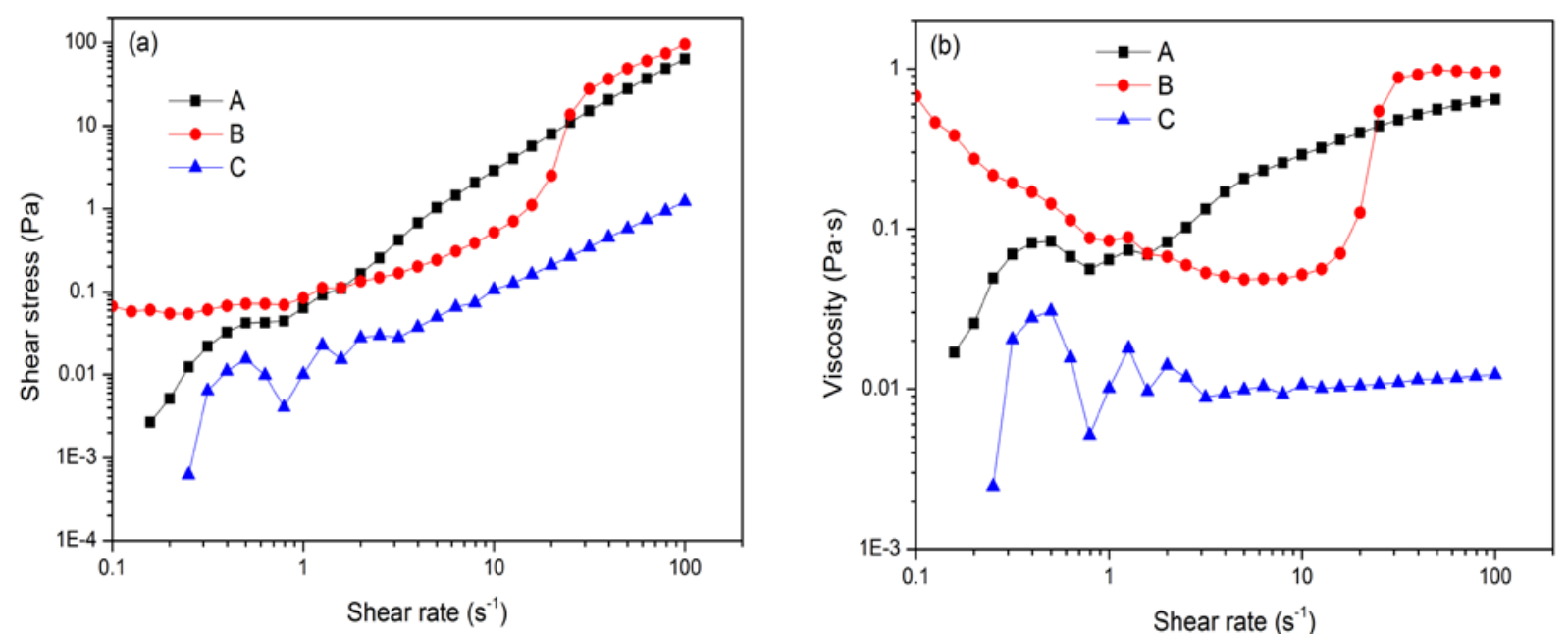

Fig. 2 Flow (a) and viscosity (b) curves for alumina slurries with the solid content of 40 vol\%

Table 2 Consistency index $K$, flow behavior index $n$ and yield stress $\tau_{y}$ of alumina slurries

\begin{tabular}{ccccc}
\hline Alumina & $K$ & $n$ & $\tau_{y}(\mathrm{~Pa})$ & $\mathrm{R}^{2}$ \\
\hline $\mathrm{A}$ & 0.19 & 1.27 & 0.042 & 0.99 \\
$\mathrm{~B}$ & 0.26 & 1.30 & 0.063 & 0.98 \\
$\mathrm{C}$ & 0.0065 & 1.14 & 0.015 & 0.99 \\
\hline
\end{tabular}

The stress dependence of the storage modulus ( $\left.G^{\prime}\right)$ and the loss modulus (G") was shown in Fig. 3. $G^{\prime}$ and G" moduli stood for solid-like and liquid-like components, respectively. The moduli values of slurry $C$ gradually decreased with the stress. While $G^{\prime}$ and $G^{\prime \prime}$ values for slurry A showed larger fluctuations. The intersection points of three slurries were (A) 0.1, (B) 0.001 and (C) $0.05 \mathrm{~Pa}$. The loss modulus (G") describing liquid-like response dominated above the intersection point, so the slurries started flowing. Though $G^{\prime}$ and $G^{\prime \prime}$ moduli of the slurry containing alumina B with larger size were less than others, them of the slurry containing powder $\mathrm{A}$ with moderate size occurred maximal value at stress of $0.038 \mathrm{~Pa}$ and minimum value of $0.3 \mathrm{~Pa}$. It can be deduced that rheological properties of alumina slurries not only depended on the size and its distribution but also on the surface charge and morphology of alumina.

Figure 4 presents the curves of frequency sweeps for alumina slurries at strain amplitude of $0.05 \%$. The variation of $G^{\prime}$ and G" moduli with frequency showed different trends. The crossover of the curves $G^{\prime}$ and $G^{\prime \prime}$ for slurry A located at $1.0 \mathrm{~Hz}$. G' modulus of slurry B dominated when the 
frequency less than $0.28 \mathrm{~Hz}$ or more than $2.5 \mathrm{~Hz}$. It was noticed that G' and G" moduli of slurry C presented less fluctuations than others, and the solid-like component ( $\left.G^{\prime}\right)$ always was higher than $G^{\prime \prime}$ at the frequency below $18.9 \mathrm{~Hz}$. By comprehensive comparison, the rheological properties of the slurry C were more stable.

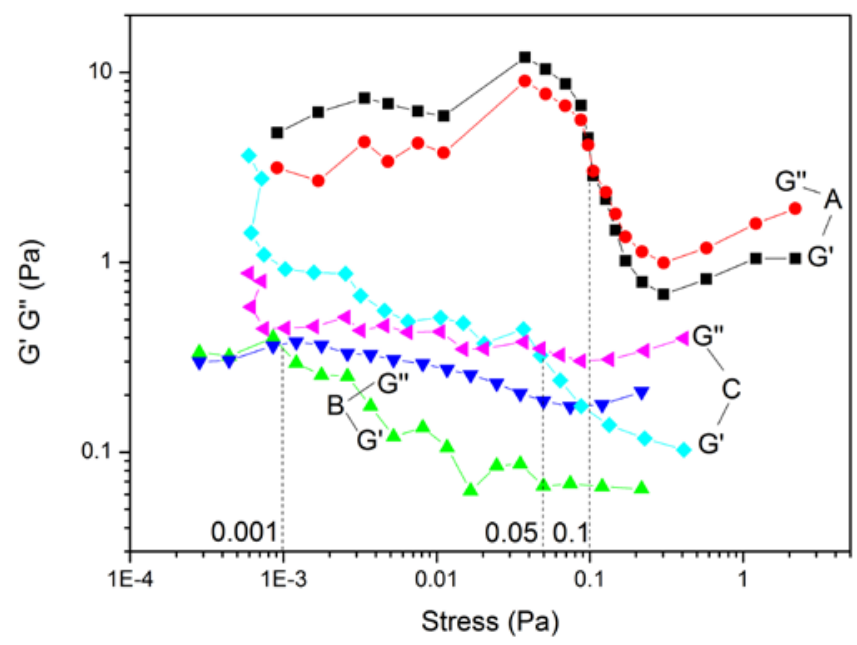

Fig. 3 Curves of store modulus G' and loss modulus G" with shear stress for alumina slurries with the solid content of $40 \mathrm{vol} \%$

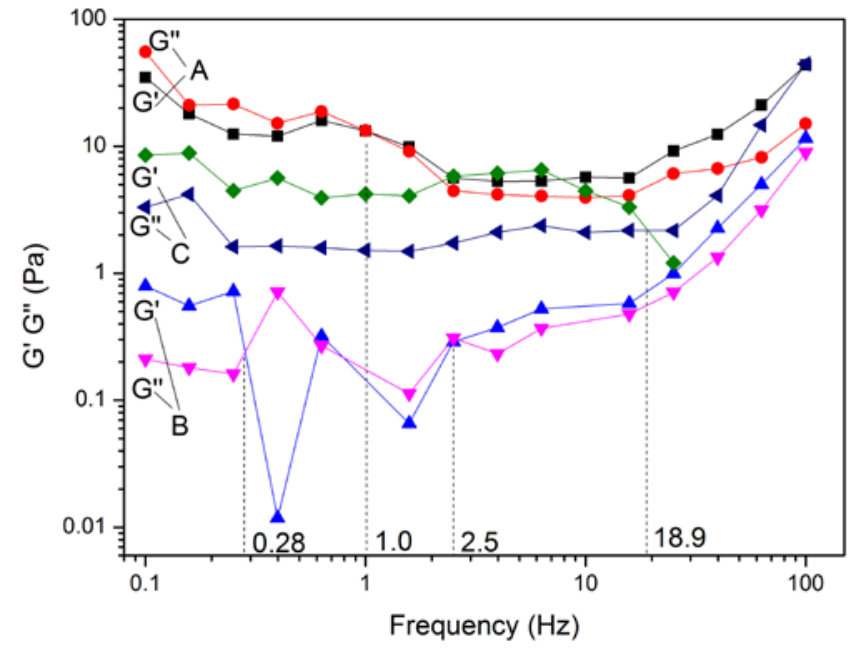

Fig. 4 Curves of store modulus G' and loss modulus G" with frequency for alumina slurries with the solid content of $40 \mathrm{vol} \%$

\section{Summary}

Effects of powder characteristics on rheological properties of alumina slurries were investigated. The conclusion follows:

(1) The particle size distribution for three kinds of alumina powders was measured and analyzed based on fractal theory. The fractal dimension of the particle size distribution for alumina powders calculated based on Rosin-Rammler distribution was inverse proportional to the uniformity of particle size.

(2) The rheological behaviors of alumina slurries tested under steady and oscillatory shear conditions exhibited distinct variations. Flow curves of alumina slurries were fitted by 
Herschel-Bulkley model. The shear-thickening behavior of slurries was attributed to the formation of hydrodynamic clusters. The variation of store and loss moduli demonstrated that the powder characteristics of alumina were crucial factors.

\section{Acknowledgement}

This research was financially supported by the National Nature Science Foundation of China (No. 51502214).

\section{References}

[1] J.F. Tong, D.M. Chen, Key factors affecting the rheological behavior of $\mathrm{Al}_{2} \mathrm{O}_{3}$ aqueous slurry, J. Chin. Ceram. Soc. 35 (2007) 1323-1326.

[2] L.F.G. Setz, A.C. Silva, S.C. Santos, S.R.H. Mello-Castanho, M.R. Morelli, A viscoelastic approach from $\alpha-\mathrm{Al}_{2} \mathrm{O}_{3}$ suspensions with high solids content, J. Eur. Ceram. Soc. 33 (2013) 3211-3219.

[3] R.G. Pileggi, A.R. Studart, V.C. Pandolfelli and J. Gallo, How mixing affects the rheology of refractory castables, Am. Ceram. Soc. Bull. 80 (2001) 27-31.

[4] A. Zupancic, R. Lapasin and A. Kristoffersson, Influence of particle concentration on rheological properties of aqueous $\alpha-\mathrm{Al}_{2} \mathrm{O}_{3}$ suspensions, J. Eur. Ceram. Soc. 18 (1998) 467-477.

[5] A. Tsetsekou, C. Agrafiotis, A. Milias, Optimization of the rheological properties of alumina slurries for ceramic processing applications Part I: Slip-casting, J. Eur. Ceram. Soc. 21 (2001) 363-373.

[6] M.S. Tsai, F.H. Yung, F.H. Yang, Boehmite modification of nano grade $\alpha$-alumina and the rheological properties of the modified slurry, Ceram. Int. 33 (2007) 739-745

[7] X.L. Xue, Fractal expression of particle size distribution, J. Qingdao Inst. Archit. Eng. 18 (1997) $1-5$.

[8] K. Yu, Z.S. Zheng, Fractal characteristics on granularity distribution of powder, Chin. J. Mater. Res. 9 (1995) 539-542.

[9] L.M. Zhang, T. Ma, J.L. Yang, Y. Huang, Rheological behavior of alumina suspensions, J. Inorg. Mater. 19 (2004) 1145-1150.

[10] P.F.G. Banfill, Rheology of fresh cement and concrete, Rheol. Rev. (2006) 61-130.

[11] K. Vance, G. Sant, N. Neithalath, The rheology of cementitious suspensions: A closer look at experimental parameters and property determination using common rheological models, Cement Concrete Comp. 59 (2015) 38-48. 